\title{
PERBANDINGAN PENGETAHUAN DAN SIKAP IBU HAMIL TENTANG RELAKSASI AROMATERAPI KOPI TERHADAP PENURUNAN TINGKAT NYERI PERSALINAN DI PMB Y KABUPATEN BANDUNG
}

\author{
Berty Risyanti \\ Program Studi Diploma Tiga Kebidanan Sekolah Tinggi Ilmu Kesehatan Dharma Husada \\ berty_ristyanti@yahoo.com
}

\begin{abstract}
ABSTRAK
Ibu hamil yang mengalami kecemasan berlebih pada masa kehamilan sampai menjelang persalinan akan berujung kepada stress yang dapat menimbulkan rasa sakit saat persalinan, dan ini harus diatasi ibu hamil yang harus memiliki ketenangan sehingga proses persalinan menjadi lancar tanpa hambatan. Ketenangan yang dibutuhkan dapat dibantu dengan menggunakan relaksasi aromaterapi seperti kopi, dengan melakukan relaksasi aromaterapi diharapkan rasa takut, panik, tegang dan tekanan-tekanan lain yang menghantui ibu hamil dalam proses persalinan dapat berkurang bahkan hilang sehingga proses persalinan dapat berjalan dengan normal. Untuk mengatasi hal tersebut harus melalui pendekatan individu secara holistik yang memengaruhi pikiran, tubuh dan emosional ibu hamil. Maka perlu dilakukan peningkatan pengetahuan, sikap dan perilaku ibu hamil tentang relaksasi aromaterapi kopi agar terjadinya penurunan pada tingkat nyeri persalinan. Sebanyak 30 orang ibu hamil yang memenuhi kriteria inklusi, yaitu Ibu hamil usia kehamilan $\geq 22$ minggu - 36 minggu yang telah mengikuti kelas ibu hamil minimal sebanyak 3 kali pertemuan, diberikan aromatherapi kopi selama mengikuti kelas ibu hamil, mengikuti penelitian selama bulan Januari 2019 - Maret 2019. Pengambilan sampel menggunakan teknik consecutive sampling. Penelitian ini menggunakan rancangan pre experimental design dengan teknik one grup pretest-posttest design. Hasil penelitian menunjukkan nilai rata-rata pengetahuan sebelum diberikan perlakuan sebesar 11,43 dan sesudah perlakuan menjadi 14,94. Nilai rata-rata sikap sebelum diberikan perlakuan sebesar 49,31 dan sesudah perlakuan menjadi 65,54 , dan terdapat perbedaan pengetahuan dan sikap ibu hamil dalam penggunaan aromatherapi kopi $(\mathrm{p}=0,001)$ dengan rata-rata pengetahuan sebesar 3,514 dan rata-rata sikap sebesar 16,229 . Berdasar hasil penelitian dapat disimpulkan terdapat perbedaan pengetahuan dan sikap ibu tentang relaksasi aromatherapi kopi terhadap penurunan tingkat nyeri persalinan.
\end{abstract}

Kata Kunci : pengetahuan, sikap, aromatherapi, kopi.

\begin{abstract}
Pregnant women who experience excessive anxiety during pregnancy until before delivery will lead to stress that can cause pain during delivery, and this must be overcome by pregnant women who must have calm so that the labor process becomes smooth without hindrance. The calm needed can be helped by using aromatherapy relaxation such as coffee, by doing aromatherapy relaxation, it is hoped that fear, panic, tension and other pressures that haunt pregnant women in labor can be reduced or even lost so that the labor process can run normally. To overcome this problem must go through a holistic individual approach that affects the mind, body and emotion of pregnant women. So it is necessary to increase the knowledge, attitudes and behavior of pregnant women about relaxation of coffee aromatherapy so that there is a decrease in the level of labor pain. A total of 30 pregnant women who met the inclusion criteria, namely pregnant women with gestational age $\geq 22$ weeks - 36 weeks who have participated in the class of pregnant women for at least 3 meetings, given coffee aromatherapy during the class for pregnant women, following the research during January 2019 March 2019. Sampling using consecutive sampling technique. This study used a pre-experimental design with one group pretest-posttest design technique. The results showed that the average value of knowledge before treatment was 11.43 and after treatment was 14.94. The average value of the attitude before being given treatment was 49.31 and after treatment was 65.54, and there was an effect of attending the class of pregnant women to increase the knowledge and attitudes of pregnant women in the use of coffee aromatherapy $(p=0.001)$ with an average knowledge of 3.514. and the average attitude is 16,229. Based on the results of the study, it can be concluded that there is an effect of the class of pregnant women on increasing the knowledge and attitudes of mothers about relaxing coffee aromatherapy on reducing the level of labor pain.
\end{abstract}

Keyword: knowledge, attitude, aromatherapy, coffee.

Jurnal Penelitian Kesehatan STIKes Dharma Husada Bandung 


\section{PENDAHULUAN}

Ibu hamil yang menjalani masa kehamilan sampai menjelang persalinan membutuhkan ketenangan agar tidak mengalami kecemasan yang berlebih sehingga proses persalinan menjadi lancar tanpa hambatan. Semakin ibu tenang menghadapi persalinan maka persalinan akan berjalan semakin lancar. Selain itu, terdapat satu alternatif alami yang bisa dilakukan oleh ibu hamil untuk membuat jiwa menjadi lebih tenang dengan energienergi positif dan membantu meringankan rasa sakit saat kontraksi.

Nyeri persalinan yang tidak tertahankan mendorong ibu bersalin mencari beberapa alternatif untuk mengatasi nyeri, diantaranya menggunakan obat penawar nyeri seperti analgetik dan sedatif. Obat-obat tersebut dapat memberikan efek samping yang merugikan misalnya fetal hipoksia, risiko depresi pernafasan neonatus, penurunan frekuensi denyut jantung dan peningkatan suhu tubuh ibu serta dapat menyebabkan perubahan pada janin. Beberapa ibu memiliki kecenderungan untuk melakukan operasi Sectio Caesarea (SC) walau tanpa indikasi yang jelas karena pada saat mengalami proses persalinan kala I fase aktif ibu mengeluhkan rasa nyeri yang hebat.

Upaya untuk mengurangi rasa nyeri persalinan dapat menggunakan metode farmakologi maupun non farmakologi. Metode non farmakologi mempunyai efek non invasive, sederhana, efektif, dan tanpa efek Jurnal Penelitian Kesehatan STIKes Dharma Husada Bandung yang membahayakan dibandingkan dengan metode farmakologi. Metode non farmakologi dalam mengatasi nyeri antara lain homeopathy, hipnobirthing, waterbirth, relaksasi, akupuntur, yoga, massage atau pemijatan, dan aromatheraphy.

Aromatherapi akan menstimulasi hipotalamus untuk mengeluarkan mediator kimia yang berfungsi sebagai penghilang rasa sakit dan menghasilkan perasaan sejahtera. Penggunaan aromaterapi secara inhalasi dapat merangsang pengeluaran endorphin sehingga dapat mengurangi nyeri. Zat endorphin merupakan zat kimia yang diproduksi oleh tubuh hasil dari stimulasi eksternal dan menghasilkan perasaan tenang, senang, rileks, terangsang, serta melemaskan otot-otot yang tegang seperti rasa sakit, dan pengerahan tenaga secara fisik. Terdapat beberapa aromaterapi yang sering digunakan dalam penurunan tingkat nyeri persalinan antara lain kopi, rose, lemon dan lavender.

Untuk mengatasi stress yang dapat menimbulkan rasa sakit saat persalinan harus melalui pendekatan individu secara holistik yang memengaruhi pikiran, tubuh dan emosional ibu hamil. Maka perlu dilakukan peningkatan pengetahuan, sikap dan perilaku ibu hamil tentang relaksasi aromaterapi kopi agar terjadinya penurunan pada tingkat nyeri persalinan.

\section{METODOLOGI PENELITIAN}

Penelitian ini menggunakan rancangan pre experimental design dengan teknik one grup 
JURNAL SEHAT MASADA VOLUME XV

pretest-posttest design yang bertujuan mencari perbandingan pengetahuan dan sikap pada ibu hamil sebelum dengan sesudah melakukan kelas ibu hamil dengan pemberian aromaterapi kopi untuk menurunkan tingkat nyeri pada persalinan. Populasi target dalam penelitian ini adalah ibu hamil yang memeriksakan kehamilan di PMB selama bulan Januari - Maret 2019, Pengambilan sampel penelitian ini menggunakan teknik consecutive sampling. Total sampel penelitian ini sebanyak 30 orang. Sebanyak 30 orang ibu hamil yang memenuhi kriteria inklusi yaitu Ibu hamil usia kehamilan $\geq 22$ minggu - 36 minggu yang telah mengikuti kelas ibu hamil minimal sebanyak 3 kali pertemuan, diberikan aromatherapi kopi selama mengikuti kelas ibu hamil, mengikuti penelitian selama bulan Januari 2019 - Maret 2019.

\section{HASIL DAN PEMBAHASAN}

A. Hasil

Tabel 1 Deskripsi Statistik dari Variabel Penelitian

\begin{tabular}{lcccc}
\hline \multirow{2}{*}{ Variabel } & \multicolumn{3}{c}{ Ukuran Statistik $^{*}$} & \\
\cline { 2 - 4 } & Mean & SD & Median & Rentang \\
\hline Pengetahuan & 79,5 & 20,68 & 85 & $30-100$ \\
Sikap & 66,79 & 5,26 & 68,12 & $46,25-80$ \\
\hline
\end{tabular}

Berdasar atas Tabel 1 dapat dilihat bahwa mean dari tiap tiap variabel yaitu pengetahuan sebesar $(79,5)$, dan sikap sebesar $(66,79)$.

Tabel 2 Perbandingan Pengetahuan dan Sikap Ibu Hamil tentang Relaksasi Aromatherapi Kopi terhadap Penurunan Tingkat Nyeri Persalinan

\begin{tabular}{|l|l|c|c|c|c|}
\hline \multicolumn{2}{|c|}{$\begin{array}{c}\text { Variabel } \\
\text { (Skala 100) }\end{array}$} & \multicolumn{2}{c|}{ Pemberian Aromatherapi Kopi } & \multirow{2}{*}{ Z $_{\text {M-w }}$ * } & Nilai p \\
\cline { 2 - 5 } Pengetahuan & Rata-rata (SD) & Ya & Tidak & & \\
& Rentang & $32,2-41,65$ & $32,3-41,73$ & & $<0,001$ \\
\hline Sikap & Rata-rata (SD) & 60,7 & 60,7 & & $<0,001$ \\
\hline
\end{tabular}

Keterangan : analisis Z dengan uji Mann - Whitney

Tabel 2 menggambarkan adanya hubungan dan bermakna antara pengetahuan dan sikap ibu hamil tentang pemberian aromatherapi kopi terhadap penurunan tingkat nyeri persalinan.

\begin{tabular}{lcccc}
\hline $\begin{array}{l}\text { Rata - rata } \\
\text { Sikap }\end{array}$ & 30 & 0 & & \\
$\begin{array}{l}\text { Mendukung } \\
\text { ( } \geq \text { Median) }\end{array}$ & 21 & 9 & 9,6 & 0,002 \\
$\begin{array}{l}\text { Tidak mendukung } \\
\text { (<Median) }\end{array}$ & 9 & 21 & & \\
\hline
\end{tabular}

Tabel 3 memperlihatkan pengetahuan ibu hamil

Tabel 3 Faktor Faktor yang Berhubungan Dengan Relaksasi Aromatherapi Kopi Selama Mengikuti Kelas Ibu Hamil

\begin{tabular}{lcccc}
\hline \multirow{2}{*}{ Variabel } & $\begin{array}{c}\text { Pemberian } \\
\text { Aromatherapi } \\
\text { Kopi }\end{array}$ & $X^{2}$ & Nilai p \\
\cline { 2 - 3 } & Ya & Tidak & \\
\hline $\begin{array}{l}\text { Pengetahuan } \\
\text { R Rata-rata }\end{array}$ & 0 & 30 & 60 & $<0,001$
\end{tabular}

tentang pemberian aromatherapi kopi terhadap penurunan tingkat nyeri persalinan mendapatkan hasil yang sama pada kategori baik, sikap ibu hamil mempunyai sikap yang mendukung terhadap pemberian aromatherapi kopi pada kelas ibu hamil.

\footnotetext{
Jurnal Penelitian Kesehatan STIKes Dharma Husada Bandung
} 


\section{B. PEMBAHASAN}

Pengetahuan adalah hasil tahu dan ini terjadi setelah orang melakukan penginderaan terhadap suatu objek tertentu. Penginderaan terjadi melalui pancaindera penglihatan, pendengaran, penciuman perasa, dan raba. Sebagian pengetahuan manusia diperoleh melalui mata dan pendengaran.

Hasil analisis statistik uji chi kuadrat menunjukan bahwa pengetahuan adalah salah satu faktor yang dapat meningkatkan ibu hamil yang mengikuti kelas ibu hamil dengan pemberian aromatherapy kopi sebesar 0,000, dari hasil tersebut dapat dilihat bahwa hubungan antara pengetahuan dengan ibu hamil yang mengikuti kelas ibu hamil dengan pemberian aromatherapi kopi signifikan. Pengetahuan ibu hamil yang tinggi maka akan semakin tinggi pula terhadap penurunan tingkat nyeri persalinan.

Sikap merupakan proses evaluatif dari dalam diri seseorang. Respons evaluatif berarti bahwa bentuk reaksi yang dinyatakan dalam sikap timbulnya didasari oleh proses evaluasi dalam diri individu yang memberi simpulan terhadap stimulus dalam bentuk baik-buruk, mendukung-tidak mendukung, positif-negatif, dan menyenangkan-tidak menyenangkan yang kemudian mengkristal sebagai potensi reaksi terhadap objek sikap.

Hasil penelitian menunjukan bahwa sikap mempunyai hubungan yang bermakna dengan meningkatkan pemberian aromatherapi kopi dalam kelas ibu hamil. Adanya hubungan sikap dengan pemberian aromatherapi kopi dalam kelas ibu hamil artinya para ibu hamil dengan sikap yang mendukung terhadap pemberian aromatherapi kopi maka akan lebih mendukung terhadap penurunan tingkat nyeri persalinan.

Hasil analisis menunjukan bahwa sikap yang mendukung atau positif adalah salah satu faktor yang dapat meningkatkan pemberian aromatherapi kopi dalam kelas ibu hamil yaitu nilai $\mathrm{p}$ sebesar 0,002 , sikap seseorang dapat tergambar dari beberapa jawaban pernyataan pada instrumen.

Pemberian aromatherapi kopi dalam kelas ibu hamil menimbulkan sikap sebagai suatu respon evaluatif. Respon hanya akan timbul apabila individu dihadapkan pada suatu stimulus yang menghendaki adanya suatu reaksi individual, dalam hal ini stimulus tersebut adalah pengetahuan yang diberikan pada kelas ibu hamil. Respon evaluatif berarti bahwa bentuk reaksi yang dinyatakan sebagai sikap itu timbulnya didasari oleh proses evaluasi dalam diri individu yang memberi kesimpulan terhadap stimulus dalam bentuk nilai baikburuk, positif-negatif, menyenangkan-tidak menyenangkan, yang kemudian mengkristal sebagai potensi reaksi terhadap objek sikap.

Pemberian aromatherapi kopi dalam kelas ibu hamil akan menimbulkan suatu sikap sosial yang terbentuk dari adanya interaksi sosial yang dialami oleh ibu hamil dengan petugas kesehatan dan para peserta kelas ibu hamil itu sendiri. Interaksi sosial tersebut meliputi hubungan antara individu dalam hal ini ibu hamil dengan lingkungan fisik maupun lingkungan psikologis di sekelilingnya. 


\section{KESIMPULAN}

Pengetahuan ibu hamil yang mengikuti kelas ibu hamil dengan diberikan aromatherapi kopi lebih baik dibandingkan dengan ibu hamil yang mengikuti kelas ibu hamil dengan tidak diberikan aromatherapi kopi.

Sikap ibu hamil yang yang mengikuti kelas ibu hamil dengan diberikan relaksasi aromatherapi kopi lebih mendukung dibandingkan dengan ibu hamil yang mengikuti kelas ibu hamil dengan tidak diberikan aromatherapi kopi.

\section{DAFTAR PUSTAKA}

1. Departemen Kesehatan Republik Indonesia. 2009. Pedoman umum manajemen kelas ibu. Depkes RI. Jakarta.

2. Departemen Kesehatan RI, Direktorat Jenderal Bina Kesehatan Masyarakat. 2001. Rencana strategis nasional making pregnancy safer (MPS) di Indonesia 2001 2010. Depkes RI \& WHO. Jakarta.

3. Utami RN. 2015. Perbedaan Efektivitas Lama Pemberian Rose Effleurage terhadap Intensitas Nyeri Kala I Fase Aktif pada Persalinan Normal Primigravida di Kota Semarang Tahun 2013. Jurnal Kebidanan. 2(4):20-30.
4. Kumalasari EP. 2012. Studi Tentang Manfaat Aromaterapi ( Aroma Lavender) Terhadap Penurunan Tingkat Nyeri Ibu Pada Persalinan Kala I Fase Aktif di Bidan Praktek Swasta Wilayah Kerja Puskesmas Ngletih Kecamatan Pesantren Kota Kediri.

5. Arikunto, S. 2012. Prosedur penelitian suatu pendekatan praktek. Rineka Cipta : Jakarta.

6. Azwar MA. 2007. Sikap manusia teori dan pengukurannya. Edisi ke-2. Pustaka Pelajar : Yogyakarta.

7. Notoatmodjo S. 2012. Promosi kesehatan dan ilmu perilaku. Rineka Cipta : Jakarta.

8. Adiyanti, Masrianto, Hakimi. Hubungan pengetahuan, sikap ibu hamil terhadap kunjungan pelayanan antenatal di kecamatan kalimanah kabupaten Purbalingga. Media Penelitian Dan Pengembangan Kesehatan Volume XI Nomor 1 Tahun 2001. Badan Penelitian Dan Pengembangan Kesehatan. Departemen Kesehatan RI. Jakarta. 2001. Hlm. 24-29.

9. Arikunto S. 2006. Prosedur penelitian, suatu pendekatan praktik. Rineka cipta. Jakarta.

10.Machfoedz I. 2010. Statistika deskriptif, bidang kesehatan, keperawatan dan kebidanan (Bio statistika). Fitramaya. Yogyakarta.

11.Hasan I. 2010. Analisis data penelitian dengan statistik. Bumi Aksara. Jakarta.

12. Riyanto, A. 2009. Pengolahan dan analisis data kesehatan. Nuha Medika. Yogyakarta. 